\title{
Arbor
}

\section{Archivo General de Palacio}

\author{
Margarita González Cristóbal
}

Arbor CLXIX, 665 (Mayo 2001), 267-286 pp.

\section{Historia}

Con la abdicación del Rey Carlos IV, la Monarquía española y su administración están sumidas en un auténtico caos, que no se remedia ante la indolencia y debilidad de Fernando VII y la altivez de la Reina. Esta situación queda bien reflejada en la administración de los Reales intereses que desde antiguo se entremezclan con los del Estado, originándose por ello continuos litigios entre el Estado y La Real Casa. Los gastos reales se confunden con los de la Familia Real, sin tasas ni consignaciones fijas, dando origen a un enorme despilfarro al que hay que poner coto.

Este caos administrativo hacía que el mismo asunto fuera tramitado a la vez en diferentes oficinas. Antes de 1814 tres eran las Dependencias que despachaban los negocios de la Real Casa y Patrimonio: Estado, Hacienda y Gracia y Justicia, pero sin determinar muy claramente las competencias de cada una, y originando por ello continuos pleitos sobre competencias. Cada Secretaría guardaba en su propio Archivo los documentos y expedientes, confusión que advertimos en los envíos de documentos a Simancas, donde hoy se encuentran custodiados documentos que deberían estar en el General de la Corona. Pero los dos oficios que en realidad englobaban todos los asuntos de la Casa del Rey, y a los que se les comunicaban las órdenes emanadas desde las Secretarías, eran los del Greffier y el Contralor. Al no haber, antes de Fernando VII, ninguna Dependencia con el nombre de Archivo, era en estas oficinas, de origen borgoñón, donde se custodiaba la documentación.

Con la llegada de José Napoleón, y sus ideas modernistas, se comienza a llevar a cabo una sistemática reforma administrativa, no 
sólo de la Real Casa, sino de las Oficinas de la Nación. El 25 de julio de 1808, se dicta un Real Decreto solicitando la entrega de toda la documentación, para poder hacer un inventario de los gastos generados por la Real Casa en años anteriores. Otro Real Decreto del 23 de septiembre de 1808, dado en Vitoria, crea el cargo de Superintendente General de la Real Casa, y entre las funciones que tiene asignadas se encuentra la custodia de Los Archivos de la Corona, siendo éste el primer documento en el que aparece el título de Archivos de La Corona. Poco a poco vamos a ir conociendo dictámenes y órdenes que hacen referencia a la documentación. El 9 de enero de 1809 el Conde de Melito pide al Ministerio de Hacienda, con el fin de centralizar todos los asuntos relacionados con la Real Casa y Patrimonio, se envíen a la Superintendencia todos los papeles y expedientes de su Departamento relacionados con los Reales Sitios.

Con el aumento de la documentación las Oficinas del Greffier y del Contralor se trasladan a la Casa denominada de los Consejos, lugar en que se quedaron mientras duraron los disturbios que por esos años se produjeron. Con la llegada de las Tropas Napoleónicas la Casa de los Consejos quedó cerrada y sellada, librándose de los expolios que sufrieron las Oficinas de Palacio.

Los diferentes Reglamentos y Etiquetas que los Reyes Españoles fueron dictando, desde Felipe II, para el gobierno de su Real Casa, obvia la palabra Archivo, y no aparece una clara disposición de custodia documental, así muchos de estos documentos quedaban en casa de los Jefes de las Oficinas. Para evitar esta dispersión, Felipe V suprime la Casa de Castilla y ordena que la documentación allí guardada pase a engrosar la del Greffier y del Contralor. En años posteriores se siguen dictando órdenes con el mismo espíritu, «archivar los documentos en estas oficinas». En cumplimiento de estas disposiciones la Oficina del Greffier se constituyó de hecho en Archivo General, sin que en realidad se le diera dicho nombre.

Fernando VII, a la vuelta de su exilio, y ante la caótica situación de la Administración, se propone llevar a cabo las reformas, que comenzó a hacer José I, y que la premura de tiempo se lo impidieron. El Real Decreto de 22 de marzo de 1814 varió la Organización de la Real Casa, idea que en realidad partió del Marqués de Sales, quien en las Cortes de 15 de enero de 1815 expuso el abandono del Patrimonio Real, y la necesidad de separar el gasto generado por la Real Casa del de la Hacienda Pública. Este Decreto sienta las bases de la nueva administración en la Casa Real, disponiendo que el Mayordomo Mayor entienda en todo lo relativo a dicha Casa, junto con la de los Palacios, 


\section{Archivo General de Palacio}

Bosques, Jardines Reales, Servidumbres, Sumillería, Caballerizas y Capilla. En esta ocasión no se olvida el Rey de crear nuevas Dependencias del Archivo particular, donde puedan custodiarse y conservarse los papeles, libros y documentos que a la sazón estaban diseminados, revueltos y confundidos en diferentes oficinas. Y para esta labor, el 15 de junio nombra al primer «Archivero General de la Real Casa, Capilla, Cámara, Caballerizas y Patrimonio Real», honor que recayó en el Grefier D. Ignacio Pérez.

Para organizar un Archivo tan confuso y de nueva creación, el 27 de junio por Real Orden comunicada se establece la primera plantilla, que en ese primer momento estaba compuesta por un Archivero, cinco oficiales, dos escribientes y dos porteros. Además el Rey manifiesta desde el primer momento el deseo de convertir el Archivo General en una oficina de primer orden, y para ello ordena la instalación en una dependencia estable, y en un local espacioso, cómodo, independiente, ventilado y seguro. La búsqueda del lugar se le encomienda el 19 de julio al Conserje General de Palacio y al Archivero. Como piezas idóneas se eligieron las ocupadas por las Compañías de Guardias Españolas, en la Plaza de Armas, al mediodía en el lugar conocido como «Arcos Nuevos». Primero se habilitó la planta baja, añadiendo según fue necesario los otras dos de Depósitos. Tanta importancia dio el Rey a estas instalaciones y a la labor de su Archivero, que en el mes de agosto dispuso que el Archivero se hiciera cargo también del Guardajoyas, instalándolo en alguna de las piezas del Archivo.

Poco a poco fueron llegando las documentos a las nuevas Dependencias desde el resto de las oficinas del Palacio Real, así como de otras partes donde fueron depositados a lo largo de tantos años de desórdenes. De esta forma llegan un número muy elevado de expedientes desde el Banco Nacional en 1815, después de ser revisados por el Archivero y varios oficiales, los depósitos allí existentes. La lentitud de la clasificación de los documentos reunidos en el Archivo desesperaba al Monarca, así Fernando VII, creyendo que se arreglaría con más personal, aunque no fuera cualificado, trasladó algunos soldados para la realización de dichas tareas.

En 1817 se publica un verdadero Reglamento para el Gobierno de la Real Casa, y allí ya se tiene en cuenta el Archivo General. A propuesta del Secretario del Despacho de Estado, el Rey dispuso que se trasladasen a Simancas todos los documentos de las Secretarias, Consejos, Tribunales y Dependencias de Gobierno hasta 1750, quedando en el Archivo de la Corona los concernientes a las Reales Servidumbres y los del Patrimonio Real. Sería largo enumerar todas las diferentes y sucesivas 
disposiciones que se fueron dando, y que dentro de la administración de la Real Casa y Patrimonio hacían referencia al Archivo de la Corona.

Así, en 1820, tras los graves acontecimientos políticos ocurridos en España, se desmembra la administración de la Real Casa y Patrimonio, ordenándose que los asuntos concernientes al Reino de Aragón se vean en la Secretaría del Despacho de Hacienda, y que los expedientes sin concluir pasen a dicha Dependencia, sin embargo, los documentos de las cuentas, escrituras, etc de los Reales Patrimonios de Valencia, Cataluña y Mallorca, así como los de las Reales Fábricas, Pinares de Valsaín y Riofrío, y los de las casas que poseía el Real Patrimonio -Turco, Alcalá, etc- deberían quedar en el Archivo hasta que fueran demandados, cosa que gracias a Dios no sucedió.

La subida al Trono de la Reina Isabel II dio origen a años de inestabilidad en todos los Gabinetes, y a un gran desorden administrativo que por supuesto se refleja en la vida del Archivo, que vio desaparecer su organización. Por circular de 30 de octubre de 1835 entran en el Archivo gran número de legajos, sin orden, obligando a los funcionarios a proceder a la clasificación urgente de tanta remesa. Los expedientes remitidos en tan confusa mezcla pertenecían a la Real Casa, la Acequia del Jarama, Casa de Campo y Real Casino, a las administraciones de Aranjuez, Sevilla, San Fernando, y a la Inspección de boca y víveres

En 1836, por Real Orden, se redistribuye la planta del Archivo y se separa el oficio de Guardajoyas, que desde Fernando VII estaba encomendada al propio Archivero Mayor, anexionándose a la Alcaydía del Real Palacio; en esa pieza quedaron custodiados, entre otros, los documentos de los Títulos de Propiedad de las fincas que constituían el Real Patrimonio, junto con los pleitos del extinguido Juzgado privativo de la Real Casa.

El año 1848 fue dramático para el Archivo, Isabel II decidió instalar dentro del recinto de Palacio el Teatro Palatino, y para buscar local idóneo dio el encargo a su Arquitecto Mayor, D. Narciso Pascual y Colomer, quien encontró en los locales del Archivo General el lugar más apropiado y "con menos coste» para la instalación. El 29 de diciembre de ese año por Real Orden «...que sin excusa ni pretexto de ningún género, por plausible que pareciese, se trasladase el material del Archivo a las habitaciones que actualmente ocupaba en el piso bajo del Real Palacio S.A. el Infante D. Fernando». Fue tal la precipitación en cumplir la Orden, que según cuenta el Sr. Güemes, ni tiempo dio para sacar la documentación de forma ordenada. Las con- 
secuencias de esta precipitación fueron las previstas: rotas las cuerdas que ataban los legajos y los papeles, se mezclaron unos con otros destruyendo en poco tiempo la labor realizada durante todos estos años. Fue corto el tiempo que ocupó el Teatro ya que por Real Decreto de 12 de julio de 1851, se dispuso la clausura del mismo, volviéndose a instalar el Archivo por Real Orden de 24 de julio de 1857.

A partir de esta fecha, el Archivo ha visto incrementado su acerbo documental con continuas y periódicas remesas, que sería muy farragoso enumerar, y que han conformado la división de los fondos documentales del actual Archivo General de Palacio.

\section{Clasificación}

El Archivo General de Palacio es un archivo eminentemente histórico por la categoría de su documentación, pero además también adquiere la categoría de archivo intermedio, por la documentación que, periódicamente, llega al mismo procedente de las diferentes Oficinas del Patrimonio Nacional, así como la procedente del Palacio de la Zarzuela, que se integra en el fondo del Reinado de Juan Carlos I.

El Archivo es de titularidad estatal y pública, y de acceso libre con tarjeta de investigador.

\section{Fondos del Archivo}

En la actualidad, el Archivo está dividido en Secciones, teniendo en cuenta la procedencia de la documentación.

\section{Administración General}

La documentación está clasificada siguiendo la moda tradicional del siglo XIX: por materias. Es de los fondos más amplios, y consta de 1.400 legajos. La documentación se remonta al Reinado de Felipe II y corresponde a la administración del Patrimonio Real, sobre todo a la gestión económica de los bienes de las Personas Reales. Son numerosas las series que conforman esta Sección por lo que citaremos algunas:

Aguas: (1592-1935) Se refiere al abastecimiento de aguas a la Casa Real y Sitios Reales. Son interesantes los documentos sobre los 
viajes de aguas de Amaniel, Fuente del Berro, el arroyo del Abroñigal, o la traída de aguas del Canal de Isabel II.

Bellas Artes: (1554-1925) Serie que agrupa la documentación con todos los ramos de las Bellas Artes: escultura, pintura, arquitectura, literatura, orfebrería y fotografía, relaciones de mecenazgo de la Casa Real, compras y adquisiciones, restauraciones, traslados, etc.

Beneficencia: (1579-1928) Serie voluminosa de la relación que la Casa Real tiene con diferentes comunidades, instituciones religiosas, hospitales, colegios, etc, por la que se conceden diversas ayudas y limosnas.

Bolsillo Secreto: (1675-1930) Cuentas de compras y gastos particulares de los Monarcas e Infantes

Fábricas: (1700-1914) Documentación de las Reales Fábricas de Tapices, Cera, Gas y Porcelana.

Inmuebles: (1570-1916) Obras en diversos inmuebles de propiedad real, alquileres, etc.

Inventarios: (1614-1910) Interesante Serie que agrupa los inventarios de los Reales Sitios realizados en diferentes épocas

Reglamentos: (1749-1923)

Titulos de Propiedad: (S. XII-XX) Escrituras de las Posesiones del Real Patrimonio, ordenadas por Administraciones o Sitios Reales.

Obras: (1554-1931) Dividida en dos partes, por un lado las obras y reparaciones del Real Alcázar de Madrid y la construcción del Nuevo Palacio Real, y por otro gastos de obras y reparaciones de los demás Palacios y Casas Reales.

\section{Reinados}

Este fondo constituye el verdadero núcleo documental del Archivo. Está compuesto por los expedientes que se generaron en los diferentes Reinados, siendo cada uno de ellos independiente del otro. Abarca desde el Reinado de Felipe II (1556) hasta D. Juan Carlos I, incluyendo la documentación de las dos Repúblicas (1873-1874 y 1931-1939), y la del General Franco (1936-1975) como Jefatura del Estado. Está subdividido por las oficinas expendedoras de documentos, y, en su defecto por materias.

Casa: Entendía en los asuntos relacionados con la Casa del Rey, su servidumbre, oficios, etc. Las materias más significativas son las relativas a la contratación de personal, tramitación de gasto ordinario o espectáculos. 
Cámara: Los temas que en ella se tramitan eran muy variados, podríamos destacar entre otros, las Ceremonias Palatinas (comidas, conciertos, tés, audiencias, besamanos, coberturas de grandes,), Etiquetas y Reglamentos con la organización de la Real Casa. Expedientes sobre Bodas Reales, Nacimientos y Fallecimientos y Exequias, Convocatorias de Cortes, Juras. Importante es el volumen documental relativo a las concesiones de condecoraciones y grandes cruces (Carlos III, Damas de la Reina M ${ }^{\mathrm{a}}$ Luisa, Toisón de Oro).

Secretaría: Oficina que entiende de los asuntos personales de los Monarcas: Correspondencia familiar, regalos.

Bureo: Oficina de Gobierno y Administración y Tribunal de la Real Casa. Sus asuntos de carácter jurídico, tanto civil como criminal, entendiendo también en Apelación.

Capilla Real: Donde se tramitan todo lo relacionado con la Iglesia: Sermones, Misas, Ofrendas, etc.

Caballerizas: En esta Oficina se tramita todo lo relacionado con el ganado, carruajes, viajes, etc.

Patrimonio: Entiende en la Administración de los Sitios Reales.

\section{Administraciones Patrimoniales}

En esta Sección se agrupan aquellos fondos que corresponden a las diferentes administraciones delegadas encargadas de la organización de los Sitios Reales o Posesiones de la Corona, muchas de ellas ya no pertenecen al Patrimonio Nacional porque fueron enajenadas de éste en diferentes épocas, y por distintos motivos, pasando a integrarse en sus municipios o provincias. Las materias de todas ellas son casi idénticas, con las pequeñas diferencias, en razón del fin para el que fueron creadas. Estas Administraciones o Reales Sitios son las que se detallan a continuación. Primero ofrecemos la lista de las que permanecen como Delegaciones actuales del Patrimonio Nacional:

Real Sitio de Aranjuez: 1561-2000.

La Granja de San Ildefonso: 1593-2000. Cuenta con la documentación de los Pinares de Valsaín, y la documentación de Linajes Nobles de Segovia, que vendieron dichos Pinares a la Corona. También cuenta con la importante Serie documental de la Real Fábrica de Cristales (1747-1834) con dibujos de los cristales, cuentas, estudios sobre la forma de grabar, etc.

Real Sitio de San Lorenzo de El Escorial: 1587-1000 
Reales Alcázares de Sevilla: 1591-2000

Real Sitio de El Pardo: 1557-2000

Valle de la Alcudia: 1815-1840

Aragón: 1814-1840

Bailía de Baleares: 1814-1915. La documentación antigua, desde el Rey Jaime I, está cedida al Archivo Regional del Reino de Mallorca.

Real Sitio del Buen Retiro: 1621-1868

Casa de Campo (Madrid): 1563-1926

Real Casino: 1816-1865

Castilleja de la Cuesta: 1878-1900

Bailía de Cataluña: 1814-1914

Dehesa de El Espadañal (Cáceres) 1847-1869

Real Posesión de La Florida: 1817-1910

Granada: 1808-1867

Dehesa de los Guadalupes (Cáceres): 1837-1857

Real Posesión de La Isabela (Cuenca): 1833-1868

Real Acequia del Jarama: 1823-1868

Administración subalterna de Navarra: 1814-1854

Real Sitio de San Fernando: 1753-1868

Solán de Cabras (Cuenca): 1814-1854

Soto de Roma (Granada): 1657-1859

Bailía de Valencia: 1708-1884

Real Posesión de Vista Alegre (Madrid): 1847-1856

Administración Subalterna de Valladolid: 1822-1855

Reales Patronatos

Contiene la documentación generada en aquellos Monasterios o Conventos en los que los Reyes como fundadores se convertían en sus tutores o patronos, administrando y tutelando sus bienes. Esta documentación tiene dos procedencias, por un lado la que emana de la Real Casa y sus relaciones con dichos Patronatos, y por otra la del propio Monasterio o Convento, como institución jurídica independiente. Su calidad es indudable, siendo también la más antigua de la que se custodia en el Archivo. El listado de los que integran la Sección son:

Asilo-Escuela de Párvulos de $M^{a}$ Cristina: 1893-1915: Cuentas, ingresos de niños, alimentación, adopciones, etc.

Patronato del Colegio de Nra. Sra. de los Remedios de Toledo Doncellas Nobles): 1841-2000. Fundación del Cardenal Silíceo. Los Reyes son Patronos junto con el Arzobispo de Toledo. Se conserva en él una 
interesante colección documental del Cardenal Silíceo, con cartas personales al Rey, la Carta de Fundación, Estatutos y Reglamento ,expedientes de limpieza de sangre de las colegialas, obras, cuentas, etc.

Colegio de Nra. Sra. del Loreto de Madrid: 1611-1998. Carta de fundación, compras de terrenos, inventarios, obras, incidencias con el Ayuntamiento de Madrid, construcción del convento, correspondencia, cuentas.

Real Convento de las Descalzas Reales (Madrid): 1572-2000. Fundación de la Infanta $D^{a}$ Juana de Austria, hija del Emperador. En el vamos a encontrar documentos de Tesorería, Administración del Convento, Fundaciones, Correspondencia, Inventarios, privilegios reales. Es interesante la documentación procedente de las Testamentarias de la Fundadora, Da Juana y la de la Emperatriz María

Real Convento de La Encarnación de Madrid: 1618-2000. La documentación es muy parecida a la del Convento anterior, pero su volumen es menor.

Real Convento de Nra. Sra. de Atocha: 1533-2000. La especial veneración que los Reyes tuvieron hacia este Convento hace que la documentación conservada sea muy numerosa. Expedientes sobre salidas de las Reinas al Santuario después de los partos, regalos, terrenos, Panteón de Hombres Ilustres, enterramientos y traslados.

Convento de las Maravillas de Madrid: 1623-1876. Fundación, enajenación de terrenos, inventarios, cuentas, obras, documentación de la destrucción del Convento tras un incendio, etc.

Convento y Colegio de Santa Isabel: 1571-2000. La documentación está muy fragmentada, ya que fue de los que se quemaron en 1931. Quedan las cuentas, listas de colegialas, inventarios, obras, venta de terrenos, etc.

Iglesia y Hospital del Buen Suceso: 1256-1997. Gran colección de Bulas originales desde la de Alejandro IV que en 1256 concede por privilegio la construcción del Hospital, memorias de fundaciones, ingresos de enfermos, tratamientos de enfermería, gastos. Como $\mathrm{Pa}$ rroquia de Palacio, que lo fue durante mucho tiempo, son de gran valor histórico los Libros de Bautismo, Confirmaciones, Matrimonios y Defunciones.

Iglesia Hospital de Nra. Sra. de Montserrat: 1271-1929. Hospital fundado para asistencia de los catalanes que vivían en la Corte, siendo fundador Juan I. Es interesante la colección de testamentos de los que queda como beneficiado el Hospital.

San Jerónimo el Real: 1548-1881. Destacaremos Libros Capitulares. 


\section{Margarita González Cristobal}

Monasterio de Las Huelgas y Hospital del Rey de Burgos: 1323-2000. Gran Fundación Monástica de Castilla la vieja, erigida por el Rey Alfonso VIII. Guarda una importante colección de privilegios reales en pergamino, muchos de ellos coloreados, con donaciones, pleitos, homenajes, bulas, etc. Del Hospital del Rey se conservan 3.000 volúmenes sobre medicina, enfermería, y farmacia desde el s. XVII.

Monasterio de Santa Clara de Tordesillas (Valladolid): 1316-2000. Convento fundado por Pedro I de Castilla. Extendía su poder por privilegios ganados a los Reyes por las provincias de Zamora, Avila, Segovia y Soria. Entre los privilegios citaremos el cobro del portazgo de Zamora y Avila, y el uso y disfrute de las Salinas de Añago. Es importante el volumen documental sobre los Baños Arabes y su reconstrucción.

Monasterio de San Lorenzo de El Escorial 1148-2000. Fue fundado por Felipe II en 1567, al que se anexionó un pequeño convento cercano, el. Monasterio de Parraces, y con él se incorporó su rico Archivo con documentación del año 1148. El Archivo del Monasterio de El Escorial, junto con el de Parraces, es el más numeroso de cuantos se conservan en Palacio. Está dividido por el carácter de los expedientes: reales, los que emanan directamente de la autoridad real; eclesiásticos, de la autoridad eclesiástica; y particulares, donaciones, compras, pleitos de particulares con el Monasterio. Contiene la Carta de Fundación con encuadernación típica escurialense, el testamento y codicilo del Fundador, la correspondencia de éste con los cuatro priores que intervinieron en las obras, pintores, arquitectos y demás artistas que hicieron posible la construcción del Monasterio, las memorias Sepulcrales, los libros de Reliquias que diferentes Monarcas entregaron para ser custodiadas en el Monasterio. Todo ello, como pequeña muestra, junto con los planos de la construcción, y las demás reformas que se fueron haciendo a través de los años, hacen que esta documentación sea de las más solicitadas por los investigadores.

Hay muchos más Patronatos que, de una forma $\mathrm{u}$ otra, y por un tiempo determinado estuvieron vinculados a la Corona; de ellos se conservan algunos documentos, pocos, pero dar el listado de todos ellos sería extenso por lo que remitimos a los que se conservan en el propio Archivo

\section{Capilla Real}

Su documentación se remonta a la época de Juan II, del que contamos con las disposiciones más antiguas sobre la Real Capilla. Es un fondo de 
un gran valor histórico por el contenido del mismo, entre los que descaremos, Bulas, Breves y Letras Apostólicas de Pontífices y Prelados que establecen la jurisdicción y atribuciones de la Capilla Palatina, así como la documentación generada por ésta en relación con otras iglesias $\mathrm{y}$ fundaciones.

Mención especial nos merecen los Libros Parroquiales, con registros de Bautismos, desde 1647, Matrimonios, desde 1646, Confirmaciones desde 1648 y Defunciones, desde 1756, no sólo de Personas Reales sino también de nobles que celebraron dichos sacramentos en la Real Capilla o de particulares en los que fueron padrinos los Reyes.

La documentación está dividida entre la Sección Administrativa y la de Real Capilla, trasladada al Archivo en 1940. En la Administrativa nos encontramos con el Archivo Musical, que custodia una interesante colección de 2360 partituras originales de música sacra de los siglos XVII-XIX.

\section{Jurídico}

Hasta 1815, fecha en que se creó la Junta Suprema Patrimonial de Apelaciones y la Junta de Gobierno, estuvo funcionando la Real Junta del Bureo, como organismo máximo de administración y gobierno de la Real Casa, así como Tribunal de Justicia. Entre 1820 y 1823 dejaron de funcionar todos los juzgados existentes en Palacio, y en 1836, por Real Orden, todos los asuntos judiciales que tenían Fuero de la Real Casa fueron a parar a la Justicia Ordinaria. Las fechas extremas son de 1610 a 1836 . En esta Sección se conservan los pleitos y causas que se veían en el Bureo y en los restantes juzgados de la Real Casa, además de los protocolos de las Escribanías de la Junta de Obras y Bosques.

Entre otras materias destacan: autos y pleitos por deudas, despojos, estafas, agresiones, robos, violaciones, testamentarías, abintestatos, censos, arrendamientos, permisos para obras, subastas, etc.

\section{Personal}

En ella se custodian 73.750 expedientes de cargos palatinos de todas las épocas. Cada expediente cuenta, en unos casos, con una documentación muy variada, que puede ir desde el nombramiento hasta su cese, pasando por licencias, aumentos de sueldos, gratificaciones, 
etc; aunque en otros sólo encontraremos el nombramiento o la minuta đel mismo. Por citar algunos ejemplos encontraremos expedientes personales de su relación con la Real Casa de, Velázquez, Goya, Bayeu, Madrazo, Olivieri, Saquetti, Juvara, etc, entre los artistas de las Bellas Artes, y los de Agustín Arguelles, Olózaga, etc, entre los políticos, amén de un sin número de nobles que sirvieron en algún cargo palatino.

\section{Registros}

Se trata de una Sección que complementa las restantes del Archivo y por lo mismo las materias son variadísimas: copiadores de Reales Ordenes, Cédulas Reales, libros de actas, memoriales, roles, libros de contabilidad, rentas, libros becerros, protocolos de escrituras, Real Estampilla, testamentarías reales, inventarios de bienes de los diferentes Palacios y Sitios Reales, registro del Toisón de Oro. La documentación abarca desde 1534 a 2000

\section{Planos y Dibujos}

Es una Sección que se organizó con fondos procedentes del resto de las Secciones del Archivo y en especial de los legajos del servicio de obras. Hasta la fecha hay catalogados 7.000 planos, en su mayoría de edificios, jardines y obras públicas. Se ha dividido en cuatro grandes grupos:

Madrid : Palacio Real (1617-XX)

Madrid: Capital (siglos XVII-XX)

Madrid Provincia (siglos XVII-XX)

Provincias españolas y Extranjero (siglos XVIII-XX)

\section{Fotografía Histórica}

Es un fondo de reciente incorporación al Archivo, que procede de diferentes Dependencias del Patrimonio Nacional: Biblioteca Real, Departamento de Conservación de Bienes Muebles, de los Reales Sitios y Patronatos. Está integrado por unas 100.000 fotografías desde los inicios de la misma hasta el año 1931. Cuenta con representación de todos los procesos fotográficos, desde el daguerrotipo hasta el papel 
baritado, y todos los formatos; así como el testimonio gráfico de todos los fotógrafos importantes de la época. Constituye, por tanto, una serie fundamental para la historia de la fotografía en España.

Es imposible hacer repaso, en tan pocas líneas, de todos los temas que vamos a encontrar ya que son variadísimos, y los Reyes utilizaron la fotografía como elemento propagandístico de primer orden para dar a conocer los logros de sus Reinados. Uno de los primeros fotógrafos que aparece es Charles Clifford con los reportajes de los viajes que la Reina Isabel II hace por toda España, así como las magníficas reproducciones de los Reales Sitios. Mención especial merece el álbum de calotipos que con motivo del nacimiento de la Infanta realiza en 1852.

Son abundante los retratos oficiales de los Monarcas realizados por prestigiosos fotógrafos: Debas, Barcia y Viet, Franzen, Resines, Kâulak. Contamos también con los trabajos realizados por un fotógrafo de excepción y de la Familia Real: el Infante Sebastián Gabriel.

Sobre las diferentes contiendas en Africa se conservan fotografías de Facio, Alfonso, Ortiz Echagüe, etc. Y numerosa es la colección de fotografías sobre Cacerías, Regatas e inundaciones. Hay que destacar unos 6.000 positivos sobre la primera Guerra Mundial y 12.000 negativos en placas de vidrio, magníficamente conservadas, pertenecientes al Inventario de Bienes Muebles que por encargo de Alfonso XIII se comenzó en 1916, terminándose durante la República.

\section{Archivo del Infante Don Gabriel}

Este fondo documental ingresó en el-Archivo procedente del Real Monasterio de San Lorenzo de El Escorial, donde estaba depositado, en 1964. Se trata de un Archivo familiar encabezado por el Infante Don Gabriel, hijo de Carlos III, continuado a través de cuatro generaciones. La vinculación del Gran Priorato de San Juan de Castilla y León a dicho Infante, bajo la forma de Mayorazgo-Infantazgo otorga a esta documentación una importancia mayor que la estrictamente privada o familiar. Es muy interesante para el estudio de La Mancha, con documentación de numerosas poblaciones de Toledo y de Ciudad Real como Alcázar de San Juan, Consuegra, Argamasaba, Manzanares, etc. Esta dividido en las siguientes subsecciones:

Secretaría: (1150-1839). Administración en general, alcaidías. Visitas, correspondencia, inventarios, cartas pueblas, pruebas de ingreso en la Orden de San Juan, etc. 
Decretos de S.M.:(1421-1839). Sobre gobierno y administración de estos lugares, privilegios, documentación del Gran Maestre de Malta, etc.

Contaduría: (1231-1839). Cuentas, testamentarías, órdenes, informes, compras, etc.

Anexo: (1150-1839). Títulos de Propiedad, mapas, pleitos, encomiendas, contratos matrimoniales, etc.

Posterior a 1839: (1839-1903). Asamblea de San Juan de Jerusalén, administración de fincas, testamentarías, fes de vida, audiencias, etc.

\section{Encomiendas del Infante Don Antonio Pascual}

Es el archivo privado de dicho Infante compuesto por la documentación de la administración del Priorato de las Ordenes Militares que llevó el Infante Don Antonio Pascual, cuarto hijo de Carlos III, así como la conservada anteriormente en el archivo de dicho Priorato o de las localidades incluidas en sus encomiendas.

Estos documentos son interesantes, principalmente, desde el punto de vista económico y se refieren en su mayoría a la administración, correspondencia con los administradores, estados de frutos y caudales, impuestos, subastas, arrendamientos, obras, nombramientos, títulos de propiedad, instrucciones y reglamentos, libros de tesorería y contaduría de las diferentes encomiendas, visitas. Entre las Encomiendas, que son muchas, citaremos: Castelnovo, Corral de Almaguer, Fresneda, Manzanares, Mayor de Alcañil, Piedrabuena, Villahermosa y Zalamea. Las fechas extremas de esta documentación comprenden de 1531 a 1836 .

En este pequeño repaso de las Secciones del Archivo y sus fondos, podemos observar cómo la documentación es muy variada. Estamos ante un Archivo de carácter administrativo y familiar, pero también político, ya que es el Archivo del Rey, como máxima autoridad política de la Nación.

Los expedientes de carácter personal son muy ilustrativos para el conocimiento de las Personas Reales, por ellos adivinaremos sus estados de ánimo, sus pensamientos más íntimos, sus vivencias, enfermedades, etc. De esta documentación citaremos algunos ejemplos: autógrafo de Felipe II de 1593 sobre propuesta de «recogimiento de mugeres moças perdidas», además de testamento y codicilo, ya nombrados. De Felipe V, original de su Testamento con numerosas correcciones de las cláusulas testamentarias. De Carlos IV y la Reina $\mathrm{M}^{\mathrm{a}}$ Luisa, la correspondencia con Godoy dentro de los Papeles Reservados de Fernando VII. De este Monarca son interesantes la correspondencia mantenida con sus 
cuatro mujeres cuando eran sus novias, o las Poesías de la Reina $M^{a}$ Amalia, recopiladas por el Rey. De Isabel, II la correspondencia desde París, en el exilio, con el Marqués de Novaliches, o la correspondencia particular de la Infanta $D^{a}$ Eulalia. De la Reina María Cristina de Austria contamos con muchos recuerdos personales entre los que cabe citar, la colección de flores disecadas recogidas en dos volúmenes y con una pequeña explicación de su puño y letra, o los cuadernos de pintura. De Alfonso XIII, contamos con su Diario y una magnífica colección de postales que la Reina $D^{a}$ Victoria Eugenia le envió cada día desde que partió para España hasta contraer matrimonio.

De gran valor documental son los libros de Farmacia, con las matrices de las recetas que, día a día, por consejo médico se suministraban a la Cámara Real.

\section{Estado Actual e Instalaciones}

Por lo que se refiere al estado actual de los fondos documentales, están inventariados y cuentan con ficheros convencionales organizados por Secciones, materias y cronológico. También hay algunos manuscritos de referencia, siempre de carácter individualizado.

En los últimos años se está comenzando a informatizar. Se trabaja con un ordenador central «SPARC 10» con sistema operativo SOLARIS y gestor de bases de datos BRS. La base de datos del Archivo se denomina CLIO y aún contamos con pequeñas series documentales, dentro de los Secciones informatizadas, salvo la de Personal y Fotografías que lo están al completo.

La ubicación es la misma que dio Fernando VII, aunque se han ido incorporando nuevas superficies. Está en la Plaza de la Armería, en los Arcos Nuevos. Su superficie actual es de aproximadamente 3.000 m2, dividido en tres plantas. Dos de ellas, Sótano y Planta Superior, destinadas exclusivamente a Depósito documental, y la Entreplanta - Principal, además de Depósito con estanterías de madera, - se conservan las originales mandadas hacer por Fernando VII-, están instalados las Despachos de Trabajo y la Sala de Lectura.

Los Depósitos cuentan con más de $15 \mathrm{Km}$. de estanterías donde se custodian alrededor de 120.000 .000 de expedientes entre 15.000 legajos, 34.000 cajas-legajos, 12.000 libros-registros, unos 7.500 planos y 100.000 fotografías. Los depósitos están equipados con estanterías metálicas, salvo los del piso principal que son de madera, con plataforma intermedia para aprovechar mejor la altura y de armarios compactos, 
donde la superficie lo permite. Los planos y fotos de gran tamaño se almacenan en planeros horizontales, y unos armarios especiales, hechos a medida, para las placas de vidrio. Todas las estancias de los depósitos tienen puertas metálicas, cortafuegos, alarmas y detectores de incendios con bombonas de gas halón.

La Sala de Lectura cuenta con terminales informáticos, uno con CD y dos para visualizar imágenes digitalizadas, y lectores- impresores de microfilm.

Existe un moderno servicio de Reprografía, con varias Cámaras para Microfilmar tanto en película convencional de rollo, como en microficha o ficha de apertura. En la actualidad se está procediendo a la digitalización de determinados documentos. Para ello se cuenta con dos Scaners planos y una máquina de vídeo digital, e impresoras de alta resolución. Se ha comenzado por digitalizar las fotografías y los planos, aunque también se han grabado documentos que por su importancia merecían dicho tratamiento.

\section{Bibliografía}

Catálogo de música del Palacio Real de Madrid. (1993): Madrid. Patrimonio Nacional. Fernández Bayton, G. (1981): Inventarios Reales. Testamentaria del Rey Carlos II. Madrid. Museo del Prado. Tres vol.

González Cristóbal, M. (1987): Inventario del Archivo del Monasterio de Santa Clara de Tordesillas, 1316-1936. Madrid. Patrimonio Nacional.

Inventarios Reales: Carlos III, 1789-1790. (1988). Madrid. Patrimonio Nacional. Tres vol.

Lizoain GarRido, J. M. (1985): Documentación del Monasterio de Las Huelgas de Burgos.-1116. Burgos. Fuentes Medievales Castellano-Leonesas. Cuatro vol.

Marcellán, J. (1938): Catálogo del Archivo de Música. Madrid. Palacio Real.

Morterero Simón, C. 81977): Guía del Archivo del Palacio Real de Madrid. Madrid. Patrimonio Nacional.

Mut Calafell, A. (1980): Inventario del Real Patrimonio Balear. Madrid. Sub. Gral de Archivos.

Mut Calafell, A (1980): Inventario de la Bailia de Valencia. Madrid. Sub. Gral de Archivos.

Mut Calafell, A. (1985): Inventario del Archivo del Infante D. Gabriel. Madrid. Sub Gral. de Archivos.

Palacín Gálvez, C y Martinéz García, L. (1990): Documentación del Hospital del Rey de Burgos (1136-1277). Burgos. Fuentes Medievales Castellano-leonesas. 
Exterior del archivo. Fachada del Palacio Real: arcos nuevos con la entrada al Archivo

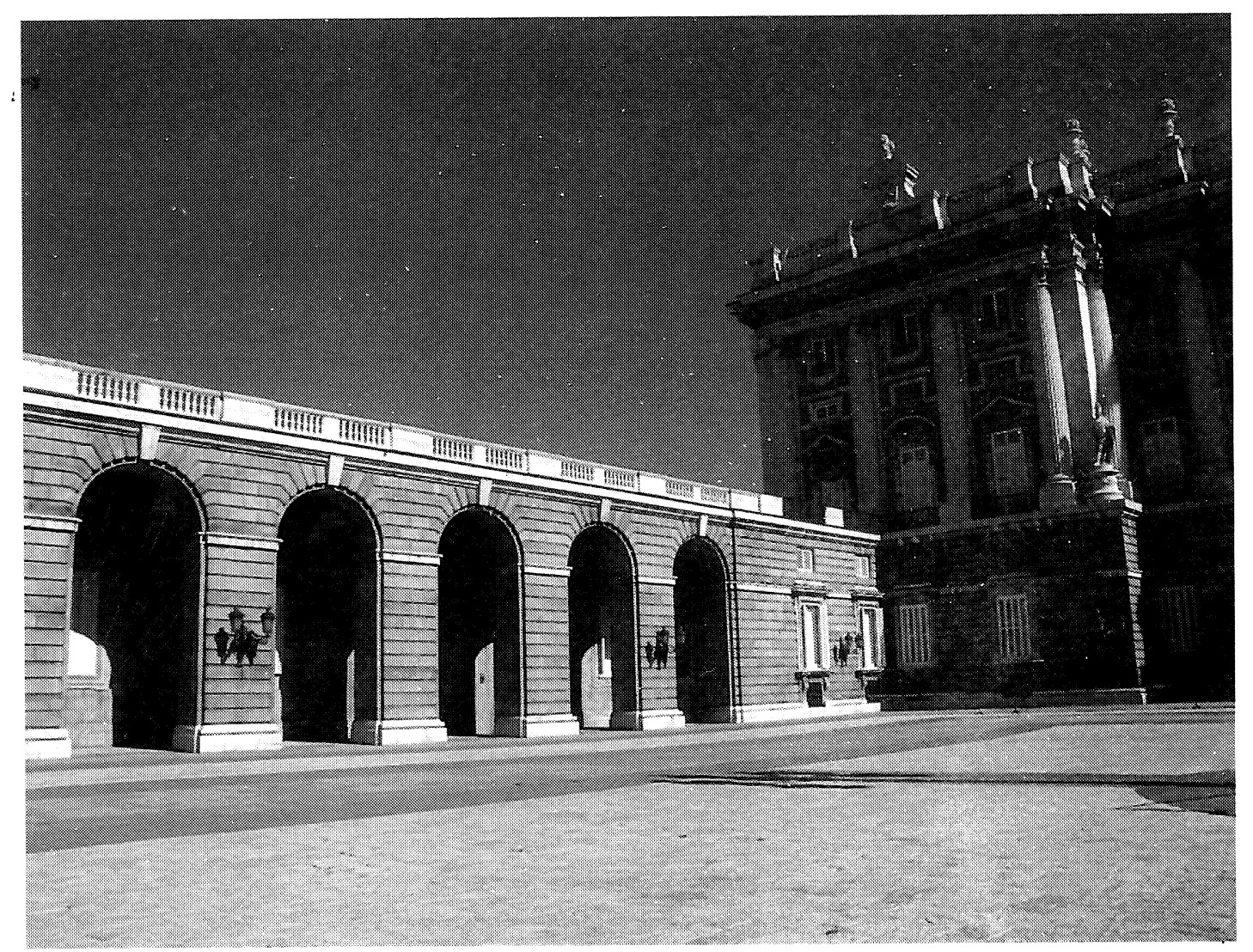




\section{Margarita González Cristobal}

284

Interior del Archivo. Estanterías de nogal mandadas hacer por Fernando VII

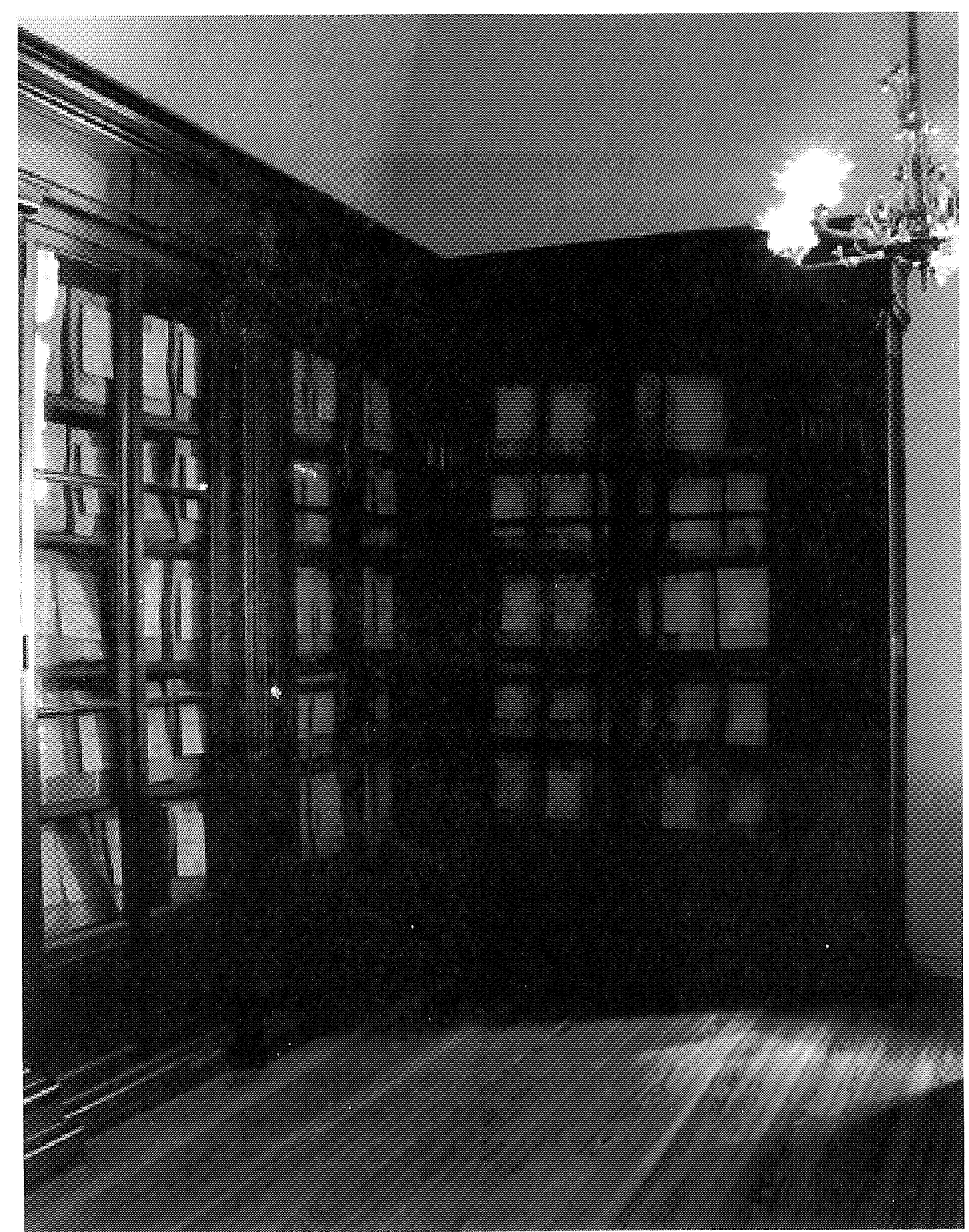




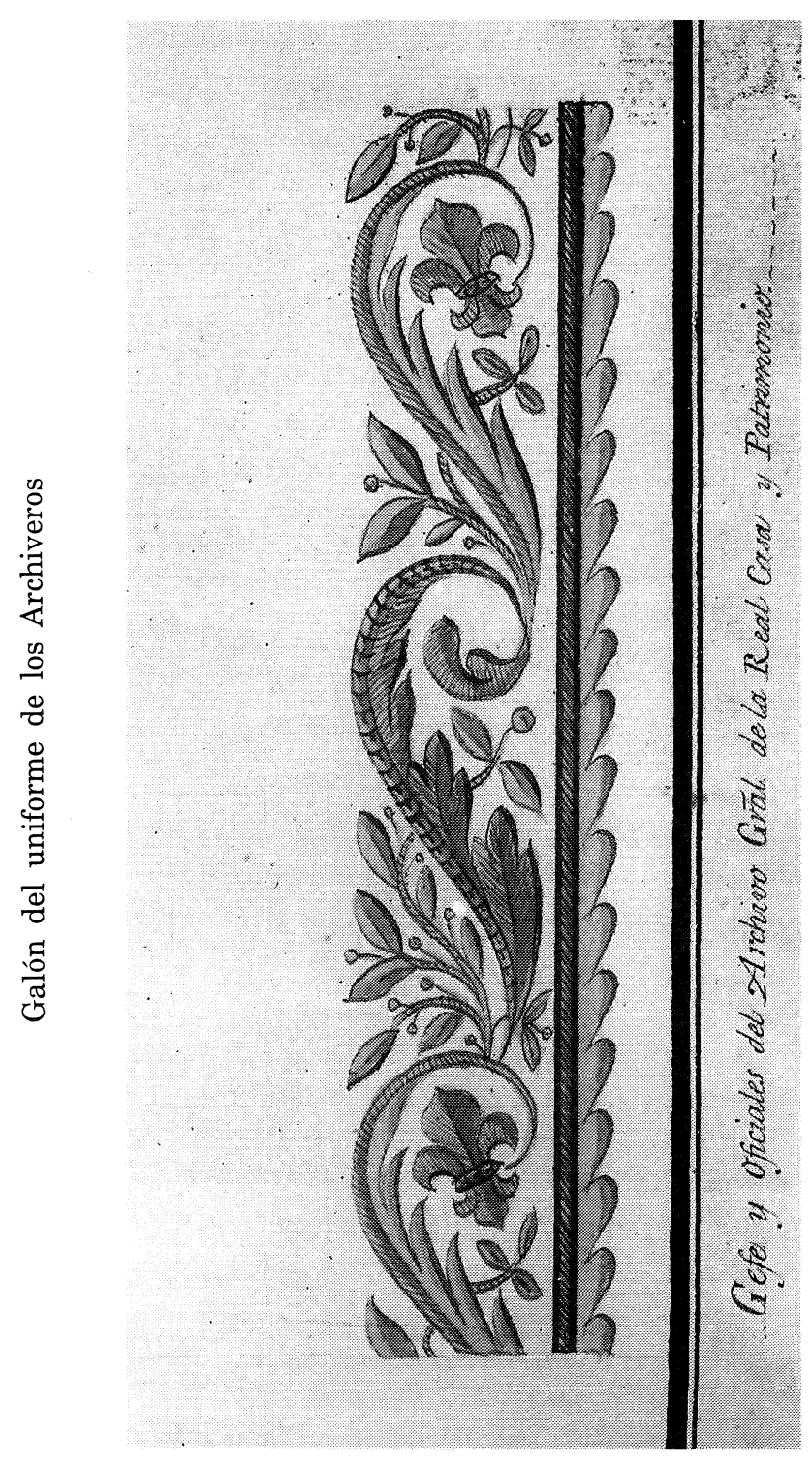


D. bordado. Mandato del Juan II ordenando como festivo el día de San Francisco. Bernuy 4 de octubre de 1408. Pergamino. Patronato de El Escoria

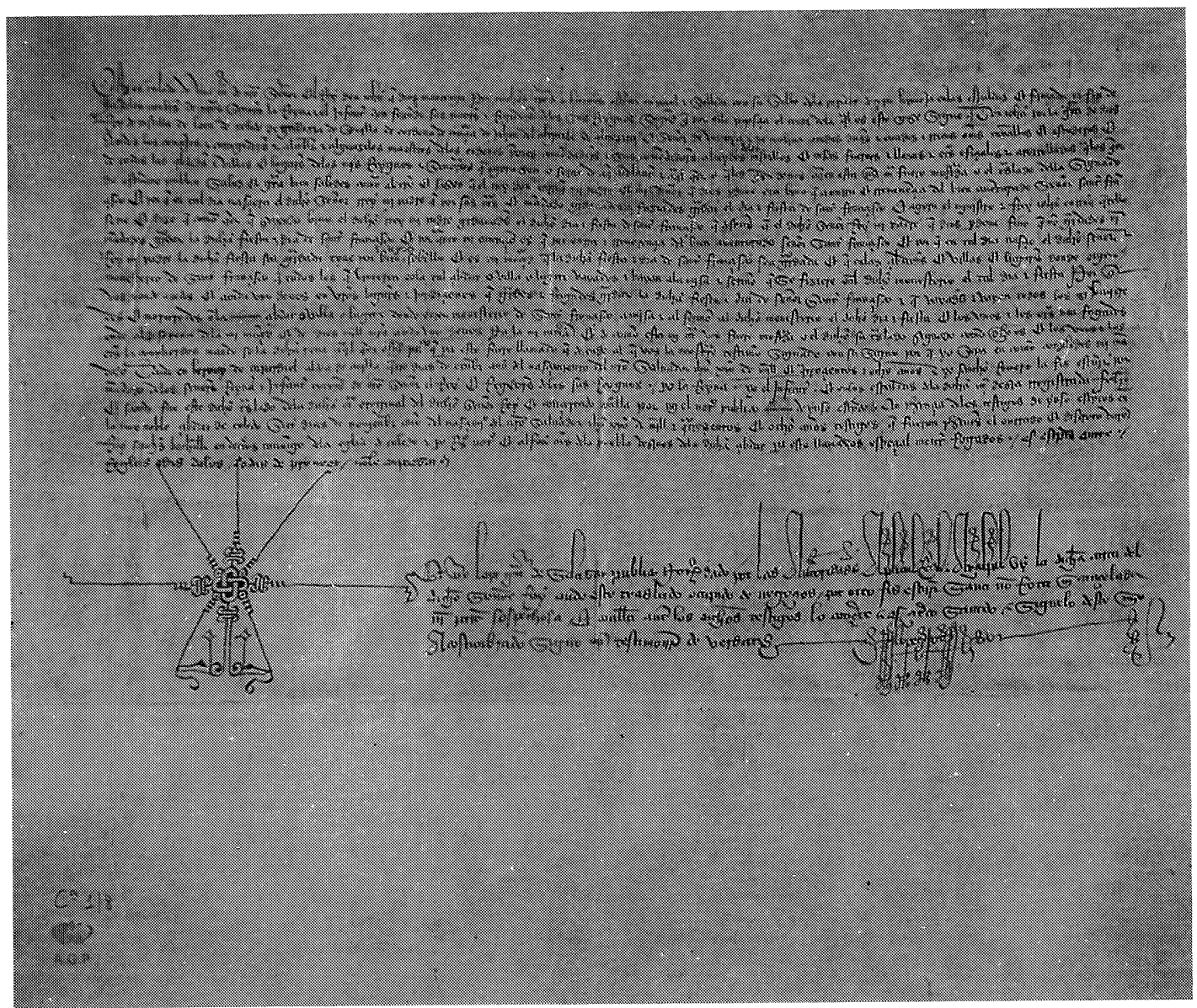

